\title{
Tinjauan Etika Bisnis Islam terhadap Praktik Jual Beli Rejected Bumbu Mie Instant
}

\author{
Rena Yolanda Firdausa*, Akhmad Yusup \\ Prodi Hukum Ekonomi Syariah, Fakultas Syariah, Universitas Islam \\ Bandung, Indonesia. \\ *rena.yolandafirdausa24@gmail.com, akhyuss91@gmail.com
}

\begin{abstract}
Islam has set rules in buying and selling both the pillars, terms, and ethics in doing business so that business people get profits and the pleasure of Allah SWT. In practice, many business people cheat by manipulating the quality of goods to gain profit. An example of a problem is buying and selling rejected instant noodle seasonings in RW 02, Cipeundeuy Padalarang Village. In this case, several sellers do not pay attention to the quality of their goods, so they are not suitable for consumption. This study aims to determine the review of Islamic business ethics on the sale and purchase of rejected instant noodle seasonings in RW 02 Cipeundeuy Padalarang Village. This study uses a qualitative approach with the type of field research - the data collection techniques in observation, interviews, and documentation. Sources of data were analyzed using inductive qualitative data analysis techniques. This study explains that there are sellers who are dishonest in mixing the quality of instant noodle seasonings so that buyers feel disadvantaged. This is not following the principles of Islamic business ethics, which require sellers to be fair, responsible, and do good. Therefore, the buyer feels aggrieved and feels cheated by the seller.
\end{abstract}

Keywords: Ethics, Buying and Selling, Rejected Product.

Abstrak. Islam telah mengatur aturan dalam jual beli baik rukun, syarat maupun etika dalam berbisnis sehingga pelaku bisnis mendapatkan keuntungan serta ridha Allah SWT. Dalam praktiknya, banyak pelaku bisnis yang berlaku curang dengan memanipulasi kualitas barang untuk mendapatkan keuntungan. Contoh permasalahan yang terjadi yaitu jual beli rejected bumbu mie instant di RW 02 Desa Cipeundeuy Padalarang. Dalam kasus ini, terdapat beberapa penjual yang tidak memperhatikan kualitas barang yang dijualnya, sehingga tidak layak untuk dikonsumsi. Penelitian ini bertujuan untuk mengetahui tinjauan etika bisnis Islam terhadap jual beli rejected bumbu mie instant di RW 02 Desa Cipeundeuy Padalarang. Penelitian ini menggunakan pendekatan kualitatif dengan jenis penelitian lapangan. Teknik pengumpulan data berupa observasi, wawancara dan dokumentasi. Sumber data dianalisis menggunakan teknik analisis data kualitatif yang bersifat induktif. Hasil penelitian menjelaskan bahwa terdapat penjual yang tidak jujur mencampurkan kualitas bumbu mie instant sehingga pembeli merasa dirugikan. Hal tersebut tidak sesuai dengan prinsip etika bisnis Islam yang mengharuskan penjual untuk bersikap adil, bertanggung jawab dan berbuat kebajikan. Oleh sebab itu, pembeli merasa dirugikan dan merasa tertipu oleh penjual.

Kata Kunci: Etika, Jual Beli, Rejected Product. 


\section{A. Pendahuluan}

Manusia merupakan makhluk sosial yang tidak bisa hidup sendiri tanpa berhubungan dengan makhluk lain dalam memenuhi kebutuhan hidupnya. Ibnu Khaldun menyatakan, bahwa manusia adalah makhluk yang bermasyarakat (al-insanu madaniyyun bi al-thab'i) mulai dari kelompok masyarakat terkecil, keluarga, sampai dengan kelompok masyarakat terbesar dengan skala wilayah yang luas. Dalam kesempatan lain beliau mengatakan, bahwa manusia adalah hayawan al-ijtima'i. Hal ini berarti manusia adalah makhluk sosial yang memerlukan bantuan orang lain dalam memenuhi kebutuhan hidupnya.

Islam mewajibkan umatnya untuk bekerja, khususnya yang memiliki tanggungan. Untuk memenuhi manusia dalam mencari rezeki, Allah Swt telah menyediakan berbagai fasilitas yang ada di bumi untuk dimanfaatkan manusia dalam mencari rezeki. Sebagaimana dijelaskan dalam firman Allah SWT Al-Mulk 15 :

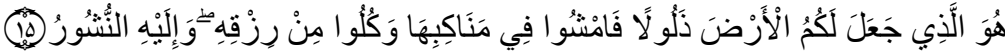

"Dialah Yang menjadikan bumi itu mudah bagi kamu, maka berjalanlah di segala penjurunya dan makanlah sebahagian dari rezeki-Nya. Dan hanya kepada-Nya lah kamu (kembali setelah) dibangkitkan."

Dengan seiring berjalannya waktu kebutuhan manusia pun semakin bertambah sehingga jual beli semakin hari semakin banyak macamnya. Terutama masyakat Indonesia tidak bisa memenuhi kebutuhannya sendiri, sehingga dapat memicu masyarakat untuk membeli makanan dengan harga yang lebih miring daripada harga aslinya. Oleh karena itu, munculah kecurangankecurangan yang dilakukan oleh pedagan, salah satunya dengan menjual bahan makanan rejected. Produk rejected/cacat adalah produk yang dihasilkan dari sebuah proses produksi yang tidak sesuai atau tidak memenuhi standar kualitas yang telah ditentukan.

Konsumen tidak mengetahui bagaimana asal-usul dari bahan makanan tersebut mulai dari produksi, pengolahan sampai dengan di tangan konsumen atau di tangan oknum-oknum penjual yang tidak bertanggung jawab. Melihat dari hal tersebut yang menjadi masalahnya adalah mengenai etika pedagang tersebut dalam menjual dagangannya karena tidak sesuai dengan nilai-nilai Islam. Aturan dan nilai-nilai Islam didalam berbisnis terdapat pada etika bisnis.

Pada dasarnya etika (akhlak) dalam ajaran Islam yaitu manusia dituntut untuk berbuat baik kepada dirinya sendiri, sesama manusia, lingkungannya, dan juga pada Tuhan selaku pencipta-Nya. Maka dari itu, dalam berbisnis manusia dituntut untuk menerapkan dasar etika bisnis Islam, yang terdiri dari prinsip-prinsip umum keesaan (tauhid), keseimbangan (equilibrium), kebebasan (free will), tanggung jawab (responsibility), dan kebajakan (ihsan).

Seperti hal nya contoh kasus di RW 02 Cipeundeuy-Padalarang, terdepat oknum penjual bumbu mie instant rejected. Bumbu tersebut didapat dari tempat pengolahan mie intsant yang ada di RW 02 Cipeundeuy-Padalarang. Pengolahan mie instant rejected merupakan bentuk CSR (Corporate Social Responsibility) sebagai aktualisasi ajaran ihsan dalam bisnis yang dilakukan oleh perusahaan mie dengan lingkungan sekitar yaitu di daerah RW 02 CipeundeuyPadalarang.

Berdasarkan latar belakang yang telah diuraikan, maka perumusan masalah dalam penelitian ini sebagai berikut: "Bagaimana tinjauan Etika Bisnis Islam terhadap jual beli bumbu mie instant rejected di RW 02 Desa Cipeundeuy - Padalarang?". Selanjutnya, tujuan dalam penelitian ini diuraikan dalam pokok-pokok sbb.

1. Untuk mengetahui etika bisnis dalam jual beli barang rejected menurut perspektif Islam.

2. Untuk mengetahui bagaimana praktik jual beli bumbu mie instant rejected di RW 02 Desa Cipeundeuy-Padalarang.

3. Untuk mengetahui analisis tinjauan Etika Bisnis Islam terhadap jual beli bumbu mie instant rejected di RW 02 Desa Cipeundeuy - Padalarang.

\section{B. Metodologi Penelitian}

Penelitian ini menggunakan metode kualitatif deskriftif. Dimana untuk mencapai tujuan dari penelitian, sangat memerlukan tinjauan lebih dalam terkait penelitian tersebut. Untuk mengetahui adanya praktik jual beli rejected bumbu mie instant oleh pegawai di tempat 
pengolahan rejected mie instant ini diperlukan metode kualitatif deskriftif karena peneliti dapat mengobservasi data dengan turun kelapangan dan mengetahui fakta-fakta yang ditemukan di lapangan. Hal tersebut dapat mempermudah dalam Teknik analisi data untuk dituangkan kedalam hasil penelitian.

Jenis data yang digunakan dalam penelitian yaitu menggunakan data lapangan (field research), dengan sumber data primer sebagau data langsung dan dara sekunder sebagai data pendukung. Teknik pengumpulan data yang digunakan yaitu menggunakan Teknik observasi, wawancara, dan dokumentasi. Sumber data dianalisis menggunakan teknik analisis data kualitatif yang bersifat induktif.

\section{Hasil Penelitian dan Pembahasan}

Jual beli dalam Islam mempunyai aturan-aturan yang salah satunya tertuang dalam prinsipprinsip etika bisnis Islam agar pelaku bisnis senantiasa menjalankan bisnisnya sesuai dengan perintah Allah SWT serta tidak melakukan kecurangan untuk mendapatkan keuntungan yang besar. Kunci etika bisnis Islam sesungguhnya terletak pada pelaku bisnis yang selalu mengedepankan moral-moral yang baik (akhlaq al-karimah). Moral atau etika merupakan perananan penting yang terdapat dalam pembentukan jiwa dan perilaku manusia. Sejalan dengan hal tersebut, Islam memberikan prinsip-prinsip dasar etika bisnis Islam yang terdiri dari prinsip Kesatuan (Tauhid/Unity), Keseimbangan (Equilibrium), Kehendak Bebas (Free Will), Tanggung jawab (Responsibility), Kebajikan (Ihsan). Berdasarkan lima prinsip dasar diatas penulis menganalisis praktik jual beli rejected bumbu mie instant di Desa Cipeundeuy RW 02. Dari hasil wawancara dan observasi dilapangan memperlihatkan bahwa terdapat ketidaksesuain dengan lima prinsip dasar etika bisnis Islam.

Islam memperbolehkan menjual barang rejected atau barang yang kualitasnya tidak baik tetapi harus dengan memperlihatkan kualitas barang tersebut bahwa barang tersebut tidak baik kualitasnya atau barang rejected. Hal tersebut berdasarkan dengan sabda Rasulullah SAW, yang artinya: "Dari Abu Hurairah ra bahwa Rasulullah pernah melewati setumpuk makanan, lalu beliau memasukkan tangannya ke dalamnya, kemudian tangan beliau menyentuh sesuatu yang basah, maka pun beliau bertanya, "Apa ini wahai pemilik makanan?" Sang pemiliknya menjawab, "Makanan tersebut terkena air hujan wahai Rasulullah." Beliau bersabda, "Mengapa kamu tidak meletakkannya di bagian makanan agar manusia dapat melihatnya? Ketahuilah, barangsiapa menipu maka dia bukan dari golongan kami.” (HR. Muslim No.102).

Berdasarkan hadits diatas sebenarnya jual beli barang rejected adalah boleh tetapi dengan memperlihatkan dan memberitahukan keaslian dari kualitas barang tersebut agar pembeli tidak merasa tertipu oleh penjual, karena orang yang sengaja menyembunyikan aib barang dagangannya adalah orang yang curang. Rasulullah SAW menegaskan bahwa pedagang yang mengetahui aib barang yang dijualnya kemudian dengan sengaja tidak memberitahukan kepada pembeli, maka praktik jual beli yang dilaksanakan haram hukumnya bagi penjual tersebut. Sebagaimana sabda Rasulullah yang artinya: "Dari Watsilah bin al-Asqa' ia berkata, Saya mendengar Rasulullah saw bersabda: "Tidak dihalalkan bagi seseorang menjual sesuatu, kecuali ia menjelaskan apa yang ada di dalamnya dan tidak dihalalkan bagi seseorang yang mengetahui hal tersebut (aib), kecuali ia menjelaskannya." (HR Ahmad, Hakim, dan Baihaqi)

Praktik jual beli rejected bumbu mie instant di Desa Cipeundeuy RW 02 Padalarang berawal dari penjual yang tidak jujur atas barang yang dijualnya terhadap pembeli dengan tidak mengatakan bahwa produk yang dijualnya merupakan produk rejected. Kemudian penjual mencampurkan kualitas bumbu yang baik dan kurang baik agar tidak mendapatkan kerugian dan mendapatkan keuntungan yang besar. Penjualpun tidak bersedia barang yang dijualnya ditukar atau dikembalikan oleh pembeli saat produk yang diterima pembeli tidak sesuai yang diinginkan. Jika terjadi hal-hal yang tidak diinginkan pembeli seperti gangguan kesehatan, penjual tidak mau tahu dan mengatakan bahwa itu adalah resiko pembeli. Hal-hal tersebut tidak sesuai dengan prinsip-prinsip etika bisnis Islam, yaitu pada prinsip Keseimbangan (Equilibrium) dalam prinsip ini penjual diharapkan menjual produk yang halal, bermutu, berkualitas baik dan bermanfaat. Terlihat dari perilaku penjual yanh mencampurkan kualitas bumbu mie instant bahwa penjual tidak memerhatikan kualitas yang dijualnya. Kemudian dalam hal ini diharapkan 
adil dan tidak ada pihak yang mendominasi sedangkan dalam praktik tersebut penjual lebih mendominasi, hal tersebut tidak dibenarkan dalam Islam, sebagaimana firman Allah SWT AnNahl 90

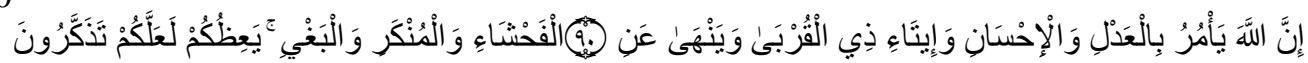

Artinya: "Sesungguhnya Allah menyuruh (kamu) berlaku adil dan berbuat kebajikan, memberi kepada kaum kerabat, dan Allah melarang dari perbuatan keji, kemungkaran dan permusuhan. Dia memberi pengajaran kepadamu agar kamu dapat mengambil pelajaran."

Berdasarkan ayat diatas jika dikaitkan dengan praktik jual beli rejected bumbu mie instant, penjual jelas tidak berlaku adil pada pembeli dengan berbuat curan mencampurkan kualitas produk yang dijualnya, padahal Allah SWT telah memerintahkan umatnya untuk senantiasa berbuat adil dan berbuat kebajikan.

Dalam prinsip Kebebasan (Free will) penjual tidak memberikan kebebasan untuk pembeli dalam memilih produknya dan juga tidak diberikan kebebasan untuk menukar atau mengembalikan produk yang dibelinya jika tidak sesuai dengan yang diinginkan.

Selain itu, praktik yang dilakukan penjual tidak sesuai dengan prinsip tanggung jawab (responsibility) karena penjual sebagai manusia harus mempertanggung jawabkan segala tindakannya. Manusia diberikan kebebasan atas segala tindakannya akan tetapi diluar itu manusia harus berani mempertanggungjawabkan segala tindakannya kelak di hadapan Allah SWT. Islam menekankan konsep tanggung jawab terhadap tindakan moral manusia sebagaimana firman Allah SWT An-Nisa' 123

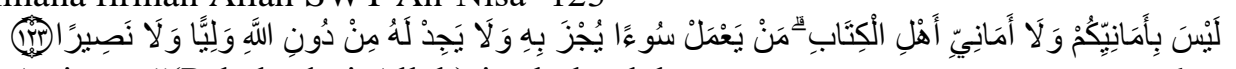

Artinya: "(Pahala dari Allah) itu bukanlah menurut angan-anganmu yang kosong dan tidak (pula) menurut angan-angan Ahli Kitab. Barangsiapa yang mengerjakan kejahatan, niscaya akan diberi pembalasan dengan kejahatan itu dan ia tidak mendapat pelindung dan tidak (pula) penolong baginya selain dari Allah."

Dalam praktiknya penjual tidak tahu dan lepas tanggung jawab atas apapun resiko yang terjadi pada pembelinya. Menurut pembeli dari rejected bumbu mie instant mengatakan bahwa pernah ada pembeli yang terganggu pencernaan nya setelah beberapa hari mengkonsumsi makanan yang diberi penyedap rejected bumbu mie instant akan tetapi penjual tidak menerima bahwa kejadian tersebut akibat dari rejected bumbu mie instant yang dijualnya. Sehingga hal tersebut sangat merugikan bagi pihak pembeli..

\section{Kesimpulan}

Berdasarkan pembahasan dalam penelitian ini, peneliti menyimpulkan beberapa hasil penelitian sebagai berikut:

1. Islam tidak melarang manusia untuk menjual barang rejected asalkan penjual tersebut menjelaskan kualitas barang yang dijual. Akan tetapi jika menjual barang rejected lebih banyak mendatangkan mudharat dengan menghilangkan hak-hak yang seharusnya didapatkan oleh pembeli daripada memberikan manfaat untuk pembeli, maka Islam tidak memperbolehkan transaksi tersebut. Sehingga dapat terbentuk hubungan yang baik antara penjual dan pembeli

2. Praktik jual beli rejected bumbu mie instant di RW 02 Padalarang dilakukan melalui perorangan saja tidak dilakukan secara bebas di pasaran. Ada dua jenis kemasan bumbu mie instant rejected yang dijual yaitu kemasan asli bumbu mie instant rejected dan kemasan re-packing seperti $1 / 4 \mathrm{~kg}, 1 / 2 \mathrm{~kg}$ dan $1 \mathrm{~kg}$. Agar tidak mengalami kerugian dalam penjualan bumbu mie instant penjual hanya memerhatikan kemasan dari bumbu mie instant rejected saja tanpa memperhatikan kualitas, dan tanggal kadaluwarsa dari bumbu mie instant rejected yang dijualnya. Pembeli da ri bumbu mie instant rejected ini biasanya merupakan ibu rumah tangga, penjual nasi goreng/mie goreng, dan penjual-penjual yang membutuhkan penyedap untuk masakannya. Menurut beberapa pembeli mereka tidak mengetahui bahwa produk tersebut merupakan rejected bumbu mie instant sehingga mereka merasa dirugikan atas kualitas produk yang mereka beli.

3. Ditinjau dari prinsip-prinsip etika bisnis Islam yaitu kesatuan (tauhid/unity), keseimbangan (keadilan/equilibrium), kehendak bebas (free will), responsibility 
(tanggung jawab), dan benevolence/kebajikan (ihsan), bahwa praktik jual beli rejected bumbu mie instant belum sepenuhnya sesuai dengan prinsip-prinsip etika bisnis Islam seperti masih terdapat penjual yang tidak jujur dengan kualitas dari rejected bumbu mie instant dan terdapat penjual yang mencampurkan kualitas dari rejected bumbu mie instant dimana itu bertentangan dengan prinsip keseimbangan (equilibrium), kehendak bebas (free will) dan responsibility (tanggung jawab). Dengan demikian pelaksanaan praktik jual beli rejected bumbu mie instant di RW 02 Cipeundeuy-Padalarang belum sesuai dengan prinsip-prinsip etika bisnis Islam.

\section{Acknowledge}

Penyusunan karya tulis ilmiah ini tidak terlepas dari dukungan berbagai pihak. Oleh karena itu, peneliti secara khusus mengucapkan terima kasih yang sebesar-besarnya kepada semua pihak yang telah membantu. Peneliti banyak menerima bimbingan, petunjuk, arahan dan bantuan serta dorongan dari berbagai pihak baik yang bersifat moral maupun material.

\section{Daftar Pustaka}

[1] Abdul Aziz, M.Ag. 2013. Etika Bisnis Perspektif Islam Implementasi Etika Islami Untuk Dunia Usaha. Bandung: Alfabeta.

[2] Amir, Syarifuddin. 2003. Garis-Garis Besar Fiqh. Jakarta: Prenada Media.

[3] Erly, Juliyani. 2016. Etika Bisnis Dalam Petspektof Islam. Jurnal Ummul Qura. Volume VII.1

[4] H. Idri. 2015. Hadis Ekonomi: Ekonomi Dalam Perspektif Hadis Nabi. Jakarta: Kencana Prenadamedia.

[5] Kusnadi Dkk. 2011. Pengantar Bisnis Yang Islami Salah Satu Wujud Nyata Kepedulian Sosial. Makassar: Alauddin University press.

[6] Syed, Nawab Haider Naqvi. 2003. Menggagas Ilmu Ekonomi Islam. Yogyakarta: Pustaka Pelajar.

[7] Veithzal Rivai dan Andi Bukhori. 2009. Islamic Economic (Ekonomi Syariah Bukan Opsi tetapi Solusi). Jakarta: Bumi Aksara. 